\title{
Metabolic evaluation of Study M05-730: LPV/r tablets QD vs. BID, co-administered with tenofovir DF + emtricitabine in ARV-naïve HIV-I infected subjects
}

\author{
BA Da Silva*, DE Cohen, TM Marsh, LM Fredrick, SE Gibbs, JM Hairrell, \\ B Bernstein, D Grant and C Naylor
}

Address: Abbott, Abbott Park, USA

* Corresponding author

from Ninth International Congress on Drug Therapy in HIV Infection

Glasgow, UK. 9-13 November 2008

Published: 10 November 2008

Journal of the International AIDS Society 2008, I I (SuppI I):PIIO doi:I0.II86/I758-2652-I I-SI-PIIO

This abstract is available from: http://www.jiasociety.org/content/II/SI/PIIO

(c) 2008 Da Silva et al; licensee BioMed Central Ltd.

\section{Background}

Evaluation of changes in lipid ratios and tools such as the Framingham risk equation may provide a more comprehensive measure of the implications of lipid changes.

\section{Methods}

664 ARV-naive HIV-1-infected subjects were randomized 1:1:1:1 to lopinavir/ritonavir (LPV/r) once-daily (QD) SGC, twice-daily (BID) SGC, QD tablet, BID tablet for eight weeks. All subjects received tenofovir (TDF) + emtricitabine (FTC) QD. At week 8, subjects taking LPV/r SGC were switched to the tablet formulation while maintaining their QD or BID dosing schedule. All subjects will be followed for up to 96 weeks. Metabolic evaluations at baseline (BL) and week 48 are presented.

\section{Summary of results}

BL characteristics were similar between QD and BID groups. Through 48 weeks, 15\% (QD) and 17\% (BID) discontinued prematurely for various reasons. Only two patients discontinued due to either elevated triglyceride (TG) or total cholesterol (TC) levels. Statistically significant mean increases were observed in individual lipid parameters through 48 weeks (Table 1). However, among all subjects combined, decreases through 48 weeks were observed for both TC:HDL ratio (from 4.40 to $4.21, \mathrm{p}=$ 0.102 ) and LDL:HDL ratio (from 2.69 to $2.34, \mathrm{p}<0.001$ ). $80 \%$ of subjects overall who had TG values $<2.825$ $\mathrm{mmol} / \mathrm{L}$ at BL maintained these levels at week 48 . Of sub- jects who had TC in the desirable NCEP range $(<5.2$ $\mathrm{mmol} / \mathrm{L}$ ) at BL, $72 \%$ maintained these levels at week 48 . $87 \%$ of subjects who had LDL in the optimal/near optimal NCEP range $(<3.38 \mathrm{mmol} / \mathrm{L})$ at $\mathrm{BL}$ also had levels in this range at week 48 . The proportion of subjects with low HDL $(<1.04 \mathrm{mmol} / \mathrm{L})$ by NCEP decreased from $60 \%$ to $33 \%$ from BL to week 48 . The mean 10 -year CV risk, including the effect of the change in age over 48 weeks, remained unchanged over 48 weeks when the LDL criteria were used $(4.63 \%$ to $4.60 \%, \mathrm{p}=0.750)$, but increased slightly when the TC criteria were used $(4.25 \%$ to $5.02 \%$, $\mathrm{p}<0.001)$. HOMA did not significantly change from baseline to week 48 (mean change +0.06 ).

\section{Conclusion}

Measures of lipid ratios and Framingham models are better assessments of cardiovascular risk than individual lipid parameters. Through 48 weeks, in subjects treated with a LPV/r-based regimen, these measures (TC:HDL and LDLC:HDL ratios) and Framingham (TC-based and LDLbased) 10-year cardiovascular risk were minimally impacted. 
Table I: Mean basline (BL), week 48, and changes from BL in lipid parameters.

\begin{tabular}{llll}
\hline & Overall $(\mathrm{N}=568$ to 575$)$ & QD $(\mathrm{N}=290$ to 295$)$ & BID (N = 276 to 280) \\
\hline TC (mmol/L) BL, Wk48, $\Delta$ & $4.00,4.82,+0.82$ & $4.02,4.77,+0.75$ & $3.97,4.87,+0.89$ \\
TG (mmol/L) BL, Wk48, $\Delta$ & $1.74,2.35,+0.61$ & $1.71,2.22,+0.51$ & $1.76,2.48,+0.72$ \\
LDL (mmol/L) BL, Wk48, $\Delta$ & $2.50,2.69,+0.19$ & $2.53,2.67,+0.14$ & $2.47,2.71,+0.24$ \\
HDL (mmol/L) BL, Wk48, & $1.02,1.21,+0.19$ & $1.03,1.22,+0.19$ & $1.01,1.20,+0.19$ \\
TC:HDL ratio BL Wk48, $\Delta$ & $4.40,4.21,-0.20$ & $4.46,4.11,-0.35$ & $4.34,4.31,-0.03$ \\
LDL:HDL ratio BL, Wk48, $\Delta$ & $2.69,2.34,-0.35$ & $2.74,2.31,-0.43$ & $2.64,2.38,-0.27$ \\
I0-yr CHD risk (LDL) (\%) BL, Wk48, $\Delta$ & $4.63,4.60,-0.04$ & $4.49,4.43,-0.06$ & $4.77,4.76,-0.01$ \\
I0-yr CHD risk (TC) (\%) BL, Wk48, & $4.25,5.02,+0.78$ & $4.29,4.89,+0.60$ & $4.21,5.17,+0.96$ \\
\hline
\end{tabular}

Publish with Bio Med Central and every scientist can read your work free of charge

"BioMed Central will be the most significant development for disseminating the results of biomedical research in our lifetime. " Sir Paul Nurse, Cancer Research UK Your research papers will be:

- available free of charge to the entire biomedical community

- peer reviewed and published immediately upon acceptance

- cited in PubMed and archived on PubMed Central

- yours - you keep the copyright 